Review Article

\title{
Perioperative Intravenous Patient-Controlled Analgesic Efficacy of Morphine with Combined Nefopam and Parecoxib versus Parecoxib in Gynecologic Surgery: A Randomized, Double-Blind Study
}

\author{
Varinee Lekprasert, ${ }^{1}$ Lapuskorn Yapanan, ${ }^{1}$ Wichai Ittichaikulthol ${ }^{D}$, ${ }^{1}$ \\ Rungrawan Buachai, ${ }^{1}$ Phimol Soisod, ${ }^{1}$ and Areepan Sophonsritsuk $\mathbb{D}^{2}$ \\ ${ }^{1}$ Department of Anesthesiology, Faculty of Medicine Ramathidodi Hospital, Mahidol University, Bangkok 10400, Thailand \\ ${ }^{2}$ Reproductive Endocrinology and Infertility Unit, Department of Obstetrics and Gynaecology, \\ Faculty of Medicine Ramathidodi Hospital, Mahidol University, Bangkok 10400, Thailand \\ Correspondence should be addressed to Areepan Sophonsritsuk; areepan.sop@mahidol.ac.th
}

Received 19 June 2020; Revised 10 September 2020; Accepted 25 January 2021; Published 12 February 2021

Academic Editor: Ronald G. Pearl

Copyright (c) 2021 Varinee Lekprasert et al. This is an open access article distributed under the Creative Commons Attribution License, which permits unrestricted use, distribution, and reproduction in any medium, provided the original work is properly cited.

\begin{abstract}
Background. Nefopam is a non-NSAIDs and opioid sparing centrally acting drug which is effective for a multimodal postoperative analgesia. The present study aimed to evaluate the analgesic efficacy of nefopam combined with parecoxib for gynecologic surgery. Methods. This randomized double-blinded control trial recruited participants $(n=72)$ who underwent gynecologic surgeries and divided them into either a nefopam or control group. The study group received parecoxib $40 \mathrm{mg}$ plus nefopam $20 \mathrm{mg}$, while the control group received parecoxib $40 \mathrm{mg}$ plus normal saline solution intravenously during open abdominal gynecological surgery. Both groups then received either nefopam or normal saline every 6 hours postoperatively for 24 hours. Intravenous patientcontrolled analgesia with morphine was given for breakthrough pain within $24 \mathrm{~h}$. The participants were evaluated for morphine consumption within 24 hours and postoperative pain using a verbal numerical rating scale (VNRS) at a postanesthetic care unit, at 6-, 12-, and 24-hour postoperative periods. Adverse effects were recorded. Results. Morphine consumption within 24 hours and adverse effects were not significantly different between both groups. Mean difference and $95 \%$ confident interval of morphine consumption between both groups was $1.00(-4.56,4.76), P=0.97$. The VNRS on movement at 6 hours after surgery of the nefopam group was significantly different from that of the control group [mean (SD), $4.14(2.11)$ vs. $5.14(1.80), P=0.04$ ]. The VNRS of the nefopam group at 12 hours after operation during resting and on movement was significantly different from that of the control group ([mean (SD), 1.47 (1.80) vs. 2.54 (2.15), $P=0.03$ ], [mean (SD), 3.22 (1.84) vs $4.17(1.74), P=0.03]$ ), respectively. Conclusions. The combined administration of nefopam and parecoxib during gynecologic surgery slightly reduced the VNRS at 6 and 12 hours postoperatively more than treatment with parecoxib.
\end{abstract}

\section{Introduction}

Postoperative pain is the most distressed adverse event occurred after major surgery which increases morbidity and prolongs the recovery period [1-3]. Multimodal analgesia based on a combination of different pharmacologic analgesic drugs alleviates this suffering pain $[3,4]$. The advantages of this strategy include improving analgesia while decreasing doses of opioids and also reducing severity of adverse effects [3]. Drug used in multimodal analgesia including various groups of medication such as paracetamol, nonsteroidal inflammatory drugs (NSAIDs), and opioids when combined with nonopioids are not efficient in relieving pain [5].

Nefopam, a benzoxazocine derivative, was developed in the early 1970s as an antidepressant medication [6]. It is a non-NSAID and nonopioid analgesic (NOA) centrally 
acting drug which is used as a multimodal analgesia in the fields of general surgery, orthopedics, and gynecology $[1,2,7]$. The drug mechanism is mainly the inhibition of reuptake for serotonin, norepinephrine, and dopamine. Nefopam also modulates glutamatergic transmission by inhibiting $\mathrm{N}$-methyl-D-aspartate (NMDA) receptors [8]. It exerted the synergistic action with ketoprofen in relieving moderate to severe pain after minor surgery [9] In addition, it decreased opioid consumption when used as a coanalgesic agent following laparoscopic abdominal surgery $[8,10]$; however, no systemic NSAIDs were used in these study. The only study that demonstrated its role as a multimodal analgesia with systematic NSAIDs was performed in a patient undergoing total hip arthroplasty [11].

Previous studies comparing more than one NOA combined with morphine for postoperative surgery are very limited, with the majority of the studies being on opioid and one NOA, either NSAIDs, paracetamol, or nefopam, which showed the morphine sparing effect. Therefore, we hypothesized that the combination of 2 NOAs and opioid would produce an additional effect for decreasing postoperative pain after major abdominal surgery. The aim of this study was to investigate the analgesic efficacy and side effects of nefopam combined with parecoxib in open gynecologic surgery.

\section{Materials and Methods}

This prospective randomized controlled trial (RCT) was approved by the Ethical Clearance Committee on Human Rights Related to Researches Involving Human Subjects, Faculty of Medicine, Ramathibodi Hospital (MURA208/ 327). The study recruited patients who underwent gynecologic surgeries between August 2018 and July 2019. The participants and assessors were blinded to the treatment groups. This trial was registered at clinicaltrials.in.th (TCTR 20180808001).

All seventy-two patients aged 20-65 years with American Society for Anesthesiologists (ASA) physical status 1-2 who were scheduled for open hysterectomy under general anesthesia were enrolled to the study. The exclusion criteria included patient refusal to participate in the study, a body mass index $(\mathrm{BMI})>35 \mathrm{~kg} / \mathrm{m}^{2}$, underlying diseases, i.e., liver failure (clinical and abnormal laboratory test: abnormal liver function test and prolonged prothrombin time), renal failure (glomerular filtration rate decrease $\geq 75 \%$ ), heart diseases (i.e., coronary artery disease and congestive heart disease), history of convulsion, history of psychologic disorder or taking monoamine oxidase inhibitors, inability to understand the verbal numerical rating scale (VNRS) (VNRS: $0=$ no pain, $10=$ the most severe pain imaginable), chronic pain, or known allergy to drugs in our protocol.

The patients were randomized into 2 groups using blockof-four computer-generated randomization. They blindly received either parecoxib and nefopam (nefopam group) or parecoxib and normal saline (NSS) (control group). In the operating room, the patient underwent general anesthesia and standardized monitoring of noninvasive blood pressure, heart rate, pulse oximetry, and electrocardiography. The baseline pain score and all vital signs were obtained. After preoxygenation with $100 \%$ oxygen for 3-5 minutes, anesthesia was induced with propofol $(1.5-2.5 \mathrm{mg} / \mathrm{kg})$, atracurium $(0.5 \mathrm{mg} / \mathrm{kg})$ or cisatracurium $(0.2 \mathrm{mg} / \mathrm{kg})$, and fentanyl (1-2 mcg/kg). Subsequently, anesthesia was maintained with oxygen, nitrous oxide, seveflurane, or desflurane (1.0-1.5 minimum alveolar concentration (MAC)) with additional atracurium or cisatracurium as needed.

Nefopam $20 \mathrm{mg}$ in NSS $100 \mathrm{~mL}$ and parecoxib $40 \mathrm{mg}$ were administered intravenously to the participants in the nefopam group, while the control group received parecoxib $40 \mathrm{mg}$ and NSS intravenously during closing the abdominal wall. Nefopam $20 \mathrm{mg}$ in NSS $100 \mathrm{~mL}$ was injected intravenously every 6 hours $(h)$ for $24 \mathrm{~h}$ postoperatively to the participants in the nefopam group, whereas the ones in the control group received NSS $100 \mathrm{~mL}$ every $6 \mathrm{~h}$. Neostigmine $(0.05 \mathrm{mg} / \mathrm{kg})$ and atropine $(0.02 \mathrm{mg} / \mathrm{kg})$ were administered for reversal of neuromuscular relaxation before finishing the operation.

Pain intensity was assessed in the postanesthetic care unit using the VNRS at $1 \mathrm{~h}$ after operation. If the VNRS was more than 4 points, patients were administered morphine $3 \mathrm{mg}$ until pain intensity less was than 4 points. Intravenous patient-controlled analgesia (IV-PCA) with morphine (protocol: morphine $1 \mathrm{mg} /$ dose, lock-out interval of 5 minute, 4-hours limit of $40 \mathrm{mg}$ and no basal infusion) was given for breakthrough pain within $24 \mathrm{~h}$. The participants were then evaluated for postoperative pain using the VNRS at 6,12 , and $24 \mathrm{~h}$ after surgery by the nurses blinded to group assignment. Postoperative hemodynamic parameters such as blood pressure, heart rate, and adverse effects including nausea, vomiting, dry mouth, sweating, arrhythmia, and apnea were carefully evaluated and recorded.

Primary and secondary outcomes were dosages of morphine consumption within $24 \mathrm{~h}$ postoperative and the VNRS at 1, 6, 12, and $24 \mathrm{~h}$ after operation, as well as adverse effects, respectively.

The sample size was calculated based on our pilot study. The results showed that nefopam combined with parecoxib and parecoxib only reduced the $24 \mathrm{~h}$ postoperative morphine consumption from $15.0 \pm 3.8$ to $12.0 \pm 4.7 \mathrm{mg}$. The number of 32 participants per group will provide $80 \%$ power to detect the equal difference in $24 \mathrm{~h}$ morphine consumption at a 2-sided alpha of 0.05 . The definite number of participants per group was 36 after compensation of data loss.

All analyses were performed by SPSS for Windows Version 20.0. The data were expressed as mean, median, standard deviation (SD), and percentage as appropriate characteristics. Between-group comparisons were analyzed using the independent samples $t$-test or Mann-Whitney $U$ test where appropriate. Categorical variables were compared between groups using the chi-square test. Pain scores were analyzed by mixed-effects maximum likelihood regression. A $P$ value $<0.05$ was considered statistically significant.

\section{Results}

Our study recruited 72 participants excluding 1 participant due to patient refusal (Figure 1). The demographic data, for 


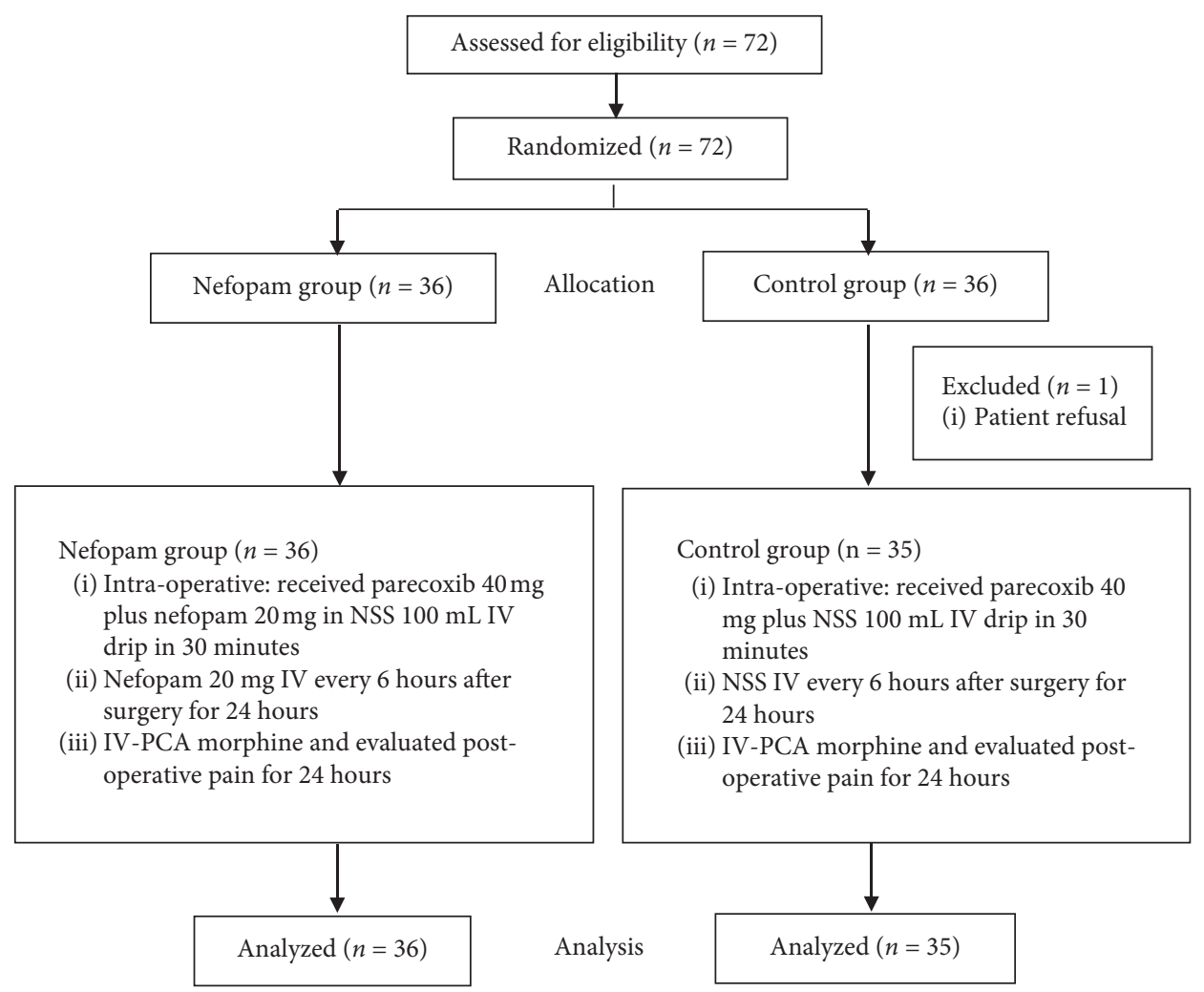

Figure 1: A study flow chart.

example, ASA physical status and operative data, were not significantly different between both groups (Tables 1 and 2). There were no significant differences in the dosage of morphine consumption in 24-hour, side effects, and hemodynamic parameters between both groups (Table 3 and 4). Pain scores were not significantly influenced by the intervention, nefopam vs. control, as shown by mixed-effect maximum likelihood regression $(P=0.058)$ (Figure 2.). Interestingly, the postoperative pain score on movement at $6 \mathrm{~h}$ and the pain score both at rest and on movement at $12 \mathrm{~h}$ were significantly lower in the nefopam group than the control groups ( $P=0.04,0.03$, and 0.03 , respectively) ( $\mathrm{Ta}-$ ble 5). Multiple comparisons of pain scores demonstrated that pain scores at 12 and $24 \mathrm{~h}$ after operation both at rest and movement were not significantly different which was similar between the nefopam and control group (Table 6).

\section{Discussion}

Our RCT study demonstrated the analgesic efficacy of multimodal analgesia using nefopam and parecoxib with IVPCA over parecoxib with IV-PCA. It produced an additional efficacy by decreasing the postoperative pain score on movement at $6 \mathrm{~h}$ and the pain score both at rest and on movement at $12 \mathrm{~h}$ more than parecoxib only. However, no difference of morphine was found.

Multimodal analgesia has been developed and widely used postoperatively for many type of surgeries. Drugs used in this strategy include paracetamol, NSAIDs, opioid, and a newly agent nefopam. The aims of using multimodal
Table 1: Demographic data.

\begin{tabular}{|c|c|c|c|}
\hline & $\begin{array}{l}\text { Nefopam } \\
(N=36)\end{array}$ & $\begin{array}{l}\text { Control } \\
(N=35)\end{array}$ & $\begin{array}{c}P \\
\text { value }\end{array}$ \\
\hline Age (years) & $41.9 \pm 9.6$ & $42.9 \pm 8.1$ & 0.667 \\
\hline Weight (kg) & $59.8 \pm 10.7$ & $61.9 \pm 10.2$ & 0.412 \\
\hline Height (m) & $1.6 \pm 0.1$ & $1.6 \pm 0.1$ & 0.226 \\
\hline BMI (kg.m ${ }^{-2}$ ) & $24.5 \pm 4.4$ & $24.8 \pm 3.9$ & 0.777 \\
\hline \multicolumn{4}{|l|}{ ASA } \\
\hline I & $13(36.1 \%)$ & $12(34.3 \%)$ & 0.872 \\
\hline II & $23(63.9 \%)$ & $23(65.7 \%)$ & \\
\hline \multicolumn{4}{|l|}{ Diagnosis } \\
\hline Adenomyosis & $3(8.3 \%)$ & $11(31.4 \%)$ & 0.014 \\
\hline Cervix cancer & $1(2.8 \%)$ & $0(0 \%)$ & 1.000 \\
\hline Endometrial cyst & $2(5.6 \%)$ & $0(0 \%)$ & 0.493 \\
\hline $\begin{array}{l}\text { Endometrium } \\
\text { cancer }\end{array}$ & $1(2.8 \%)$ & $0(0 \%)$ & 1.000 \\
\hline $\begin{array}{l}\text { Endometrium } \\
\text { hyperplasia }\end{array}$ & $0(0 \%)$ & $1(2.9 \%)$ & 0.493 \\
\hline Myoma uteri & $24(66.7 \%)$ & $18(51.4 \%)$ & 0.192 \\
\hline Ovarian mass & $5(13.9 \%)$ & $5(14.3 \%)$ & 1.000 \\
\hline \multicolumn{4}{|l|}{ Type of operation } \\
\hline TAH & $36(100.0 \%)$ & $35(100.0 \%)$ & 0.117 \\
\hline TAH with BSO & $26(72.2 \%)$ & $19(54.3 \%)$ & - \\
\hline Operation time (min) & $164.2 \pm 53.8$ & $162.3 \pm 62.9$ & 0.893 \\
\hline Blood loss $(\mathrm{mL})$ & $344.4 \pm 383.9$ & $437.7 \pm 508.7$ & 0.385 \\
\hline \multicolumn{4}{|l|}{ Type of wound incision } \\
\hline Midline & $12(33.3 \%)$ & $8(22.9 \%)$ & 0.327 \\
\hline Pfannenstiel & $24(66.7 \%)$ & $27(77.1 \%)$ & \\
\hline Incision length $(\mathrm{cm})$ & $11.9 \pm 2.9$ & $11.8 \pm 2.8$ & 0.898 \\
\hline
\end{tabular}

Data are represented as mean \pm standard deviation or number (\%) where appropriate. Abbreviations: TAH, total abdominal hysterectomy; BSO, bilateral salpingo-oophorectomy. 
TABLE 2: Intraoperative characteristics.

\begin{tabular}{lccc}
\hline & Nefopam $(N=36)$ & Control $(N=35)$ & $P$ value \\
\hline Type of operation & & & \\
TAH only & $10(27.8 \%)$ & $16(45.7 \%)$ & 0.117 \\
TAH with BSO & $26(72.2 \%)$ & $19(54.3 \%)$ & $162.3 \pm 62.9$ \\
Operation time (min) & $164.2 \pm 53.8$ & $85.1 \pm 30.7$ & 0.893 \\
Intraoperative fentanyl use (mg) & $86.9 \pm 27.1$ & $437.7 \pm 508.7$ & 0.910 \\
Blood loss (mL) & $344.4 \pm 383.9$ & $8(22.9 \%)$ & 0.385 \\
\hline Type of wound incision & $12(33.3 \%)$ & $27(77.1 \%)$ & 0.327 \\
Midline & $24(66.7 \%)$ & $11.8 \pm 2.8$ & 0.898 \\
Pfannenstiel & $11.9 \pm 2.9$ & & \\
Incision length (cm) & & & \\
\hline
\end{tabular}

Data are represented as mean \pm standard deviation or number (\%) where appropriate. Abbreviations: TAH, total abdominal hysterectomy; BSO, bilateral salpingo-oophorectomy.

TABle 3: Morphine consumption of nefopam and control groups.

\begin{tabular}{lccccc}
\hline & \multicolumn{2}{c}{$\begin{array}{c}\text { Nefopam } \\
(N=36)\end{array}$} & \multicolumn{2}{c}{ Control $(N=35)$} & \multicolumn{2}{c}{ Mean difference } & $P$ value \\
& Mean & SD & Mean & SD & $(95 \%$ CI $)$ \\
\hline Morphine consumption in 24 hours $(\mathrm{mg})$ & 19.58 & 9.64 & 19.49 & 10.05 & $1.00(-4.56,4.76)$ \\
\hline
\end{tabular}

Abbreviations: PO, postoperation; SD, standard deviation; CI, confidence interval.

TABLE 4: Adverse effects of nefopam and control groups.

\begin{tabular}{lccc}
\hline & $\begin{array}{c}\text { Nefopam } \\
(N=36)\end{array}$ & $\begin{array}{c}\text { Control } \\
(N=35)\end{array}$ & $P$ value \\
\hline Nausea and & $14(38.9 \%)$ & $12(34.3 \%)$ & 0.687 \\
vomiting & $6(16.7 \%)$ & $4(11.4 \%)$ & 0.735 \\
Dry mouth & $3(8.3)$ & $0(0.0 \%)$ & 0.239 \\
Sweating & $1(2.8 \%)$ & $0(0.0 \%)$ & 1.000 \\
\hline
\end{tabular}

Data are represented as number (\%).

analgesia are to decrease postoperative pain and undesirable effects of opioids [4]. Opioids acting centrally are widely used postoperatively despite of their adverse effects such as nausea, vomiting, bowel ileus, respiratory depression, and delirium. NSAIDs act at both the central and the peripheral level, by reducing prostaglandin production $[12,13]$. Nefopam is a nonopioid analgesic drug with a centrally acting mechanism which has an equivalent analgesic effect to NSAIDs [1, 2, 6]. Yoon et al. [14] demonstrated the comparable analgesic efficacy using nefopam only and a combination of IV-PCA using of morphine and ketorolac in laparoscopic gynecologic surgery. Many studies showed lower incidence of postoperative nausea and vomiting in the nefopam group $[11,15,16]$. Several recent studies demonstrated the beneficial effect of nefopam, a significant postoperative opioid sparing effect, as an agent in multimodal analgesia $[6,8,17,18]$. Jin el al. [19] reported significantly lower PCA fentanyl consumption and pain score in the nefopam-combined fentanyl group than the fentanyl group in open laparotomy. Mimoz et al. [20] performed an RCT study comparing control, nefopam, and propacetamol, all combined with morphine IV-PCA in hepatic resection. They reported that the postoperative pain intensity at 4 and
$24 \mathrm{~h}$ and morphine consumption at immediately after extubation, 1-4, 4, and $24 \mathrm{~h}$ were significantly lower in the nefopam group. This finding is in line with the laparoscopic cholecystectomy study in which analgesic efficacies of ketorolac and nefopam combined with fentanyl were similar [21]. However, studies about multimodal analgesia using more than one NOA have been published scarcely.

Our RCT demonstrated the minimal enhancement of the analgesia of the combination of nefopam, parecoxib, and morphine IV-PCA for postoperative open major gynecologic surgery. The combined drugs significantly decrease pain intensity on movement at $6 \mathrm{~h}$ and both at rest and on movement at $12 \mathrm{~h}$ compared with parecoxib and morphine IV-PCA, but there was no significant difference of morphine consumption. Our results were inconsistent with the OCTOPUS study, a multicenter, double-blinded RCT, which compared different NOA combinations with morphine for postoperative analgesia [22]. The treatment groups in the OCTOPUS study included control, paracetamol (P), nefopam $(\mathrm{N})$, ketorolac $(\mathrm{K}), \mathrm{PN}, \mathrm{PK}$, and PNK. There was no significant difference of pain score and morphine consumption at 24 and $48 \mathrm{~h}$ after operation compared between NK vs. K. However, there were significant differences of (1) morphine consumption at 24 and $48 \mathrm{~h}$ between control vs. NPK and N vs. NPK and (2) the pain score at $24 \mathrm{~h}$ between control vs. NPK, N vs. NPK, and P vs. NPK. The study was stopped early because of the ethical concern of the investigators. The number of recruited participants was several fold lower than the calculated samples ( $n, 27$ vs. 125 per group). Therefore, the analgesic effect when comparing between NSAID and nefopam could not be analyzed due to the inadequate power of the sample size. Moreover, many kinds of operation were evaluated which was different from our study. 


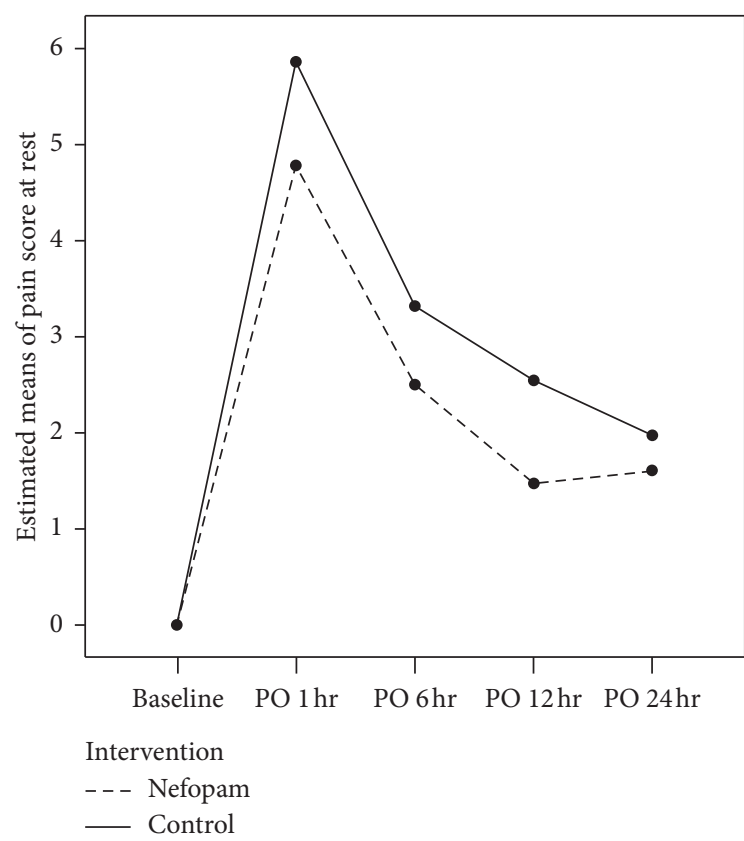

(a)

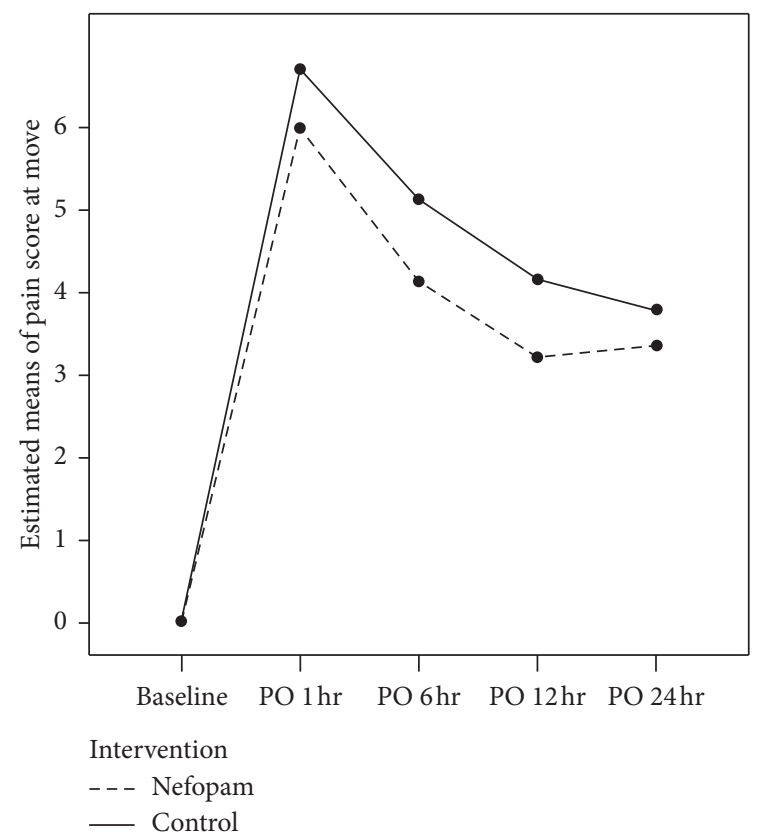

(b)

Figure 2: Estimated means of pain score analyzed by mixed-effects regression between nefopam and control at various time points. (a) At rest: no effect of intervention on the estimated mean pain score, $P$ value $=0.058$; (b) at movement: intervention, nefopam and control, affecting the estimated pain score, $P$ value $=0.046$.

TABLE 5: Pain score assessment during the operation and after the operation.

\begin{tabular}{|c|c|c|c|c|c|c|c|}
\hline & & \multicolumn{2}{|c|}{ Nefopam $(N=36)$} & \multicolumn{2}{|c|}{ Control $(N=35)$} & \multirow{2}{*}{$\begin{array}{l}\text { Mean difference } \\
\quad(95 \% \mathrm{CI})\end{array}$} & \multirow{2}{*}{$P$ value } \\
\hline & & Mean & $\mathrm{SD}$ & Mean & SD & & \\
\hline \multirow{2}{*}{ Baseline } & At rest & 0 & 0 & 0 & 0 & $0(0,0)$ & 1.00 \\
\hline & On movement & 0 & 0 & 0.03 & 0.17 & $-0.03(-0.09,0.03)$ & 0.32 \\
\hline \multirow{2}{*}{ PO 1 hour } & At rest & 4.78 & 3.08 & 5.86 & 3.29 & $-1.08(-2.59,0.43)$ & 0.16 \\
\hline & On movement & 6.00 & 3.10 & 6.71 & 2.94 & $-0.71(-2.14,0.72)$ & 0.32 \\
\hline \multirow{2}{*}{ PO 6 hours } & At rest & 2.50 & 2.15 & 3.31 & 2.42 & $-0.81(-1.90,0.27)$ & 0.14 \\
\hline & On movement & 4.14 & 2.11 & 5.14 & 1.80 & $-1.00(-1.94,-0.07)$ & 0.04 \\
\hline \multirow{2}{*}{ PO 12 hours } & At rest & 1.47 & 1.80 & 2.54 & 2.15 & $-1.07(-2.00,-0.13)$ & 0.03 \\
\hline & On movement & 3.22 & 1.84 & 4.17 & 1.74 & $-0.95(-1.80,-0.10)$ & 0.03 \\
\hline \multirow{2}{*}{ PO 24 hours } & At rest & 1.61 & 1.67 & 1.97 & 2.11 & $-0.36(-1.26,0.54)$ & 0.43 \\
\hline & On movement & 3.36 & 1.69 & 3.80 & 1.78 & $-0.44(-1.26,0.38)$ & 0.29 \\
\hline
\end{tabular}

PO, postoperation; SD, standard deviation; CI, confidence interval.

The morphine consumption at 24 and $48 \mathrm{~h}$ between nefopam plus parecoxib and parecoxib only was not different but not the pain score on movement at $6 \mathrm{~h}$ and the pain score both at rest and on movement at $12 \mathrm{~h}$. It could be possible because the pain score was not high, and then, the patients ignored administering morphine IV-PCA during changing the position. Therefore, a reduction in morphine consumption is not a good indicator of the benefit of adding analgesic. Moreover, data from a systemic study showed that morphine sparing was not changing parallel to morphinerelated adverse effects [5]. Interestingly, a few prior studies evaluated the pain score at 6 or $12 \mathrm{~h}$ after operation as our study, a period at which patients often have severe pain.
Previous studies have reported sweating, tachycardia, and hypertension as common side effects of nefopam [6], but the incidence of these side effects in this study was similar in both groups. The frequency of adverse effects was not found to reduce by the combination of these, likely because of the relatively low incidence of adverse effects arising from this medications However, it is an advantage to use the minimal dose of each drug.

Limitations of the study were the subjective data of pain scores. Pain evaluation was a self-assessment using the VNRS that was individual dependent and multifactorial involvement such as pain evaluation at the bed time of the patients. Moreover, when the pain scores were low, it could 
TABLE 6: Multiple comparison of pain scores during at rest and movement between nefopam and control groups.

\begin{tabular}{|c|c|c|c|c|c|c|c|c|c|}
\hline Parameter & & Diff & $95 \%$ CI & $P$ value & Parameter & & Diff & $95 \% \mathrm{CI}$ & $P$ value \\
\hline $\begin{array}{l}\text { At rest } \\
\text { Nefopam }\end{array}$ & & & & & $\begin{array}{l}\text { At rest } \\
\text { Control }\end{array}$ & & & & \\
\hline \multirow[t]{4}{*}{ Baseline } & PO $1 \mathrm{hr}$ & -4.8 & $-6.3,-3.2$ & $<0.001$ & Baseline & PO $1 \mathrm{hr}$ & -5.9 & $-7.5,-4.2$ & $<0.001$ \\
\hline & PO 6 hrs & -2.5 & $-3.5,-1.4$ & $<0.001$ & & PO 6 hrs & -3.3 & $-4.5,-2.1$ & $<0.001$ \\
\hline & PO 12 hrs & -1.5 & $-2.4,-0.5$ & $<0.001$ & & PO 12 hrs & -2.5 & $-3.6,-1.4$ & $<0.001$ \\
\hline & PO $24 \mathrm{hrs}$ & -1.6 & $-2.4,-0.8$ & $<0.001$ & & PO $24 \mathrm{hrs}$ & -1.9 & $-3.0,-0.9$ & $<0.001$ \\
\hline \multirow{3}{*}{ PO $1 \mathrm{hr}$} & PO 6 hrs & 2.3 & $0.6,3.9$ & 0.002 & PO $1 \mathrm{hr}$ & PO $6 \mathrm{hrs}$ & 2.5 & $1.1,4.0$ & $<0.001$ \\
\hline & PO 12 hrs & 3.3 & $1.6,5.0$ & $<0.001$ & & PO $12 \mathrm{hrs}$ & 3.3 & $1.7,4.9$ & $<0.001$ \\
\hline & PO $24 \mathrm{hrs}$ & 3.2 & $1.6,5.7$ & $<0.001$ & & PO $24 \mathrm{hrs}$ & 3.9 & $2.4,5.4$ & $<0.001$ \\
\hline \multirow[t]{2}{*}{ PO $6 \mathrm{hrs}$} & PO $12 \mathrm{hrs}$ & 1.0 & $0.2,1.8$ & 0.004 & PO 6 hrs & PO $12 \mathrm{hrs}$ & 0.8 & $-0.3,1.8$ & 0.312 \\
\hline & PO $24 \mathrm{hrs}$ & 0.9 & $0,1.8$ & 0.062 & & PO $24 \mathrm{hrs}$ & 1.3 & $0.4,2.3$ & 0.002 \\
\hline PO $12 \mathrm{hrs}$ & PO $24 \mathrm{hrs}$ & 0.1 & $-0.5,0.8$ & 1.000 & PO $12 \mathrm{hrs}$ & PO $24 \mathrm{hrs}$ & 0.6 & $-0.3,1.4$ & 0.576 \\
\hline At movement & & & & & At movement & & & & \\
\hline Nefopam & & & & & Control & & & & \\
\hline \multirow[t]{4}{*}{ Baseline } & PO $1 \mathrm{hr}$ & -6.0 & $-7.5,-4.4$ & $<0.001$ & Baseline & PO $1 \mathrm{hr}$ & -6.7 & $-8.2,-5.2$ & $<0.001$ \\
\hline & PO $6 \mathrm{hrs}$ & -4.1 & $-5.2,-3.1$ & $<0.001$ & & PO $6 \mathrm{hrs}$ & -5.1 & $-6.0,-4.2$ & $<0.001$ \\
\hline & PO $12 \mathrm{hrs}$ & -3.2 & $-4.1,-2.3$ & $<0.001$ & & PO $12 \mathrm{hrs}$ & -4.1 & $-5.0,-3.3$ & $<0.001$ \\
\hline & PO $24 \mathrm{hrs}$ & -3.4 & $-4.2,-2.5$ & $<0.001$ & & PO $24 \mathrm{hrs}$ & -3.8 & $-4.7,-2.9$ & $<0.001$ \\
\hline \multirow[t]{3}{*}{ PO $1 \mathrm{hr}$} & PO 6 hrs & 1.9 & $0.3,3.4$ & 0.010 & PO $1 \mathrm{hr}$ & PO $6 \mathrm{hrs}$ & 1.6 & $0.3,2.9$ & 0.009 \\
\hline & PO $12 \mathrm{hrs}$ & 2.8 & $1.1,4.4$ & $<0.001$ & & PO 12 hrs & 2.5 & $0.9,4.2$ & $<0.001$ \\
\hline & PO $24 \mathrm{hrs}$ & 2.6 & $1.4,3.9$ & $<0.001$ & & PO $24 \mathrm{hrs}$ & 2.9 & $1.4,4.4$ & $<0.001$ \\
\hline \multirow[t]{2}{*}{ PO 6 hrs } & PO $12 \mathrm{hrs}$ & 0.9 & $0.08,1.8$ & 0.024 & PO 6 hrs & PO 12 hrs & 1.0 & $0,1.9$ & 0.034 \\
\hline & PO $24 \mathrm{hrs}$ & 0.8 & $-0.1,1.7$ & 0.157 & & PO $24 \mathrm{hrs}$ & 1.3 & $0.4,2.3$ & 0.001 \\
\hline PO $12 \mathrm{hrs}$ & PO $24 \mathrm{hrs}$ & -0.1 & $-1.0-0.7$ & 1.000 & PO 12 hrs & PO $24 \mathrm{hrs}$ & 0.4 & $-0.2,0.9$ & 0.567 \\
\hline
\end{tabular}

PO, postoperation; SD, standard deviation; CI, confidence interval; Diff, difference; hr, hour.

not reflect the morphine consumption. Patient satisfaction should be evaluated in the future study for better analysis. Since we gave only 1 time of parecoxib which can maintain analgesia for $12 \mathrm{~h}$, the latter $12 \mathrm{~h}$ postoperative analgesia could be explained by the effect of parecoxib and morphine IV-PCA. The future study may focus on other analgesic such as paracetamol, other kinds of NSAIDs, or even more multiple combined drugs.

\section{Conclusions}

Administration of nefopam combined with parecoxib is slightly better than parecoxib only for acute postoperative pain control at 6 and $12 \mathrm{~h}$ for gynecologic operations. This could help patients to ease their early ambulation. Morphine consumption in 24 hours was not significantly different in both groups with comparable adverse effects.

\section{Data Availability}

All data generated or analyzed during this study are included in this manuscript.

\section{Ethical Approval}

This study was approved by the Ethical Clearance Committee on Human Rights Related to Researches Involving Human Subjects, Faculty of Medicine, Ramathibodi Hospital (MURA208/327), and registered on Clinicaltrials.in.th (TCTR 20180808001).

\section{Conflicts of Interest}

The authors declare that there are no conflicts of interest regarding the publication of this article.

\section{Acknowledgments}

The authors would like to thank Rojnarin Komonhirun for statistical analysis. This study was funded by a grant from the Faculty of Medicine, Ramathibodi Hospital, Mahidol University, Bangkok, Thailand (grant no. RF-61075).

\section{References}

[1] P. Girard, M. Chauvin, and M. Verleye, "Nefopam analgesia and its role in multimodal analgesia: a review of preclinical and clinical studies," Clinical and Experimental Pharmacology and Physiology, vol. 43, no. 1, pp. 3-12, 2016.

[2] B. Y. Hwang, J. Y. Kwon, D. W. Lee, E. Kim, T. K. Kim, and H. K. Kim, "A randomized clinical trial of nefopam versus ketorolac combined with oxycodone in patient-controlled analgesia after gynecologic surgery," International Journal of Medical Sciences, vol. 12, no. 8, pp. 644-649, 2015.

[3] V. Martinez, H. Beloeil, E. Marret, D. Fletcher, P. Ravaud, and L. Trinquart, "Non-opioid analgesics in adults after major surgery: systematic review with network meta-analysis of randomized trials," British Journal of Anaesthesia, vol. 118, no. 1, pp. 22-31, 2017.

[4] H. Kehlet and J. B. Dahl, "The value of "multimodal" or "balanced analgesia" in postoperative pain treatment," $A n$ esthesia \& Analgesia, vol. 77, no. 5, pp. 1048-1056, 1993.

[5] N. Elia, C. Lysakowski, and M. R. Tramer, "Does multimodal analgesia with acetaminophen, nonsteroidal antiinflammatory 
drugs, or selective cyclooxygenase-2 inhibitors and patientcontrolled analgesia morphine offer advantages over morphine alone? Meta-analyses of randomized trials," Anesthesiology, vol. 103, no. 6, pp. 1296-1304, 2005.

[6] M. S. Evans, C. Lysakowski, and M. R. Tramer, "Nefopam for the prevention of postoperative pain: quantitative systematic review," British Journal of Anaesthesia, vol. 101, no. 5, pp. 610-617, 2008.

[7] M. Kakkar, S. Derry, R. A. Moore, and H. J. McQuay, "Single dose oral nefopam for acute postoperative pain in adults," Cochrane Database of Systematic Reviews, vol. 97, no. 3, Article ID Cd007442, 2009.

[8] T. Zhao, Z. Shen, and S. Sheng, "The efficacy and safety of nefopam for pain relief during laparoscopic cholecystectomy: a meta-analysis," Medicine (Baltimore), vol. 97, no. 10, Article ID e0089, 2018.

[9] N. Delage, H. Maaliki, H. Beloeil, D. Benhamou, and J. X. Mazoit, "Median effective dose (ED50) of nefopam and ketoprofen in postoperative patients: a study of interaction using sequential analysis and isobolographic analysis," Anesthesiology, vol. 102, no. 6, pp. 1211-1216, 2005.

[10] E. M. Kim, J. H. Jeon, M. H. Chung et al., "The effect of nefopam infusion during laparascopic cholecystectomy on postoperative pain," International Journal of Medical Sciences, vol. 14, no. 6, pp. 570-577, 2017.

[11] F. Remerand, C. Le Tendre, P. Rosset et al., "Nefopam after total hip arthroplasty: role in multimodal analgesia," Orthopaedics \& Traumatology: Surgery \& Research, vol. 99, no. 2, pp. 169-174, 2013.

[12] J. S. Walker, "NSAID: an update on their analgesic effects," Clinical and Experimental Pharmacology and Physiology, vol. 22, no. 11, pp. 855-860, 1995.

[13] T. L. Yaksh, D. M. Dirig, C. M. Conway, C. Svensson, Z. D. Luo, and P. C. Isakson, "The acute antihyperalgesic action of nonsteroidal, anti-inflammatory drugs and release of spinal prostaglandin E2 is mediated by the inhibition of constitutive spinal cyclooxygenase-2 (COX-2) but not COX1," Journal of Neuroscience, vol. 21, no. 16, pp. 5847-5853, 2001.

[14] J. U. Yoon, G. J. Byeon, J. H. Cheon, Y. M. Choi, H. S. Ri, and S. W. Baik, "Post-operative intravenous patient-controlled analgesic efficacy of morphine with ketorolac versus nefopam after laparoscopic gynecologic surgery: a randomized noninferiority trial," Korean Journal of Anesthesiology, vol. 69, no. 2, pp. 161-166, 2016.

[15] K. Kim, W. J. Kim, D. K. Choi, Y. K. Lee, I. C. Choi, and J. Y. Sim, "The analgesic efficacy and safety of nefopam in patient-controlled analgesia after cardiac surgery: a randomized, double-blind, prospective study," Journal of International Medical Research, vol. 42, no. 3, pp. 684-692, 2014.

[16] C. S. Oh, E. Jung, S. J. Lee, and S. H. Kim, "Effect of nefopamversus fentanyl-based patient-controlled analgesia on postoperative nausea and vomiting in patients undergoing gynecological laparoscopic surgery: a prospective doubleblind randomized controlled trial," Current Medical Research and Opinion, vol. 31, no. 8, pp. 1599-1607, 2015.

[17] J. Y. Moon, S. S. Choi, S. Y. Lee et al., “The effect of nefopam on postoperative fentanyl consumption: a randomized, double-blind study," Korean Journal of Pain, vol. 29, no. 2, pp. 110-118, 2016.

[18] H. S. Na, A. Y. Oh, B. W. Koo, D. J. Lim, J. H. Ryu, and J. W. Han, "Preventive analgesic efficacy of nefopam in acute and chronic pain after breast cancer surgery: a prospective, double-blind, and randomized trial," Medicine (Baltimore), vol. 95, no. 20, Article ID e3705, 2016.

[19] H. S. Jin, Y. C. Kim, Y. Yoo, C. Lee, C. W. Cho, and W. J. Kim, "Opioid sparing effect and safety of nefopam in patient controlled analgesia after laparotomy: a randomized, double blind study," Journal of International Medical Research, vol. 44, no. 4, pp. 844-854, 2016.

[20] O. Mimoz, P. Incagnoli, C. Josse et al., "Analgesic efficacy and safety of nefopam vs. propacetamol following hepatic resection," Anaesthesia, vol. 56, no. 6, pp. 520-525, 2001.

[21] J. S. Son, A. Doo, Y. J. Kwon, Y. J. Han, and S. Ko, “A comparison between ketorolac and nefopam as adjuvant analgesics for postoperative patient-controlled analgesia: a randomized, double-blind, prospective study," Korean Journal of Anesthesiology, vol. 70, no. 6, pp. 612-618, 2017.

[22] H. Beloeil, P. Albaladejo, A. Sion et al., "Multicentre, prospective, double-blind, randomised controlled clinical trial comparing different non-opioid analgesic combinations with morphine for postoperative analgesia: the OCTOPUS study," British Journal of Anaesthesia, vol. 122, no. 6, pp. e98-e106, 2019. 